(3) Lacroix, A.: "Les Tectites de 1'Indochine," Arch. Mus. Hist. Nat., 6th Ser., 8, 193-236, 12 pls., 43 text figs., and bibl. of 32 titles, Paris, 1932.

(4) Fenner, Charles: "Australites" (Pt. I, 1934; Pt. II, 1935; Pt. III, 1938), Trans. Roy. Soc. South Australia, 58, 59, and 62, 8 pls., many text figs., and bibl. of 125 titles (in Pt. III).

(5) Beyer, H. Otley: "A Bibliography of Tektites," listing 450 titles, with brief abstracts and critical notes, Manila, 1939 (in press).

July 21, 1939

\title{
An Astronomical Theory of Tektites*
}

By W. CARI RUfus,

Observatory, University of Michigan, Ann Arbor

\begin{abstract}
It is supposed that the small, natural-glass bodies known as tektites were originally derived in major part from the glassy basalt, or tachylyte, which forms the deeper crustal layer of the earth, exposed chiefly on the floor of the Pacific basin, at the time of the fissional separation of the moon; furthermore, that the earthly tektites represent only a small section of the vast swarms of tiny satellites which remained revolving about the earth within the Roche limit, and particularly that section of the satellites having a revolutional period closely coinciding with the period of the earth's rotation. Such swarms would have.remained approximately above the Pacific basin, but would have gradually fallen behind and tended to be drawn to the earth, on account of perturbations resulting from the gradual retardation of the moon. Cumulative perturbations and other related factors have caused swarms of these bodies to come down to the earth at widely separated geologic periods in the earth's history, such falls having been particularly extensive along a great-circle route crossing the western edge of the Pacific basin. This circumstance would account for the great quantity and wide distribution of the Indomalaysian tektites espeaially, which are of almost identical chemical composition, while other showers of tektites came at different geologic periods and varied somewhat in composition and physical appearance.
\end{abstract}

The purpose of this communication is to outline briefly an astronomical theory of the origin of tektites, which is presented "with all the distrust that everything not a result of observation or of calculation ought to inspire"! By its very nature, the problem lies beyond the scope of observation and no direct method of attack by mathematical analysis seems possible.

The astronomical theory here proposed refers to showers of small satellites of the earth. It is based on the assumption that some of the matter separated from the earth at the time of the origin of the moon by fission ${ }^{1}$ did not immediately fall back to the earth or follow the moon, but continued to revolve about the earth for some time within the Roche limit, i.e., the distance from a planet's center within which a satellite cannot remain without danger of disruption. The Roche limit is about 2.44 times the radius of the planet. It is interesting to note in this connection that Saturn's rings, composed of discrete particles, are within this distance and its nearest satellite, Mimas, lies safely outside.

*Read at the Seventh Annual Meeting, Columbus, Ohio, December, 1939. [See the footnote to the title of the preceding paper by Professor $H$. O. Beyer.]

1 We here assume a general knowledge of the fission theory of the origin of the moon as advocated by Sir George Darwin and others. 
According to the fission theory, the action of tides raised by the sun in the primitive earth produced an elongated or pear-shaped form of that body. Separation was preceded by a figure of equilibrium consisting of two elongated masses joined by a narrow neck. This state was very unstable and the time of rupture was followed by a period of great turbulence before order was restored in the formation of a satellite. The period of the earth's rotation at that time was. about 4h8. Tidal friction has resulted in decreasing the speed of the earth's rotation (lengthening the day) and by a transfer of angular momentum to the moon, its distance and period of revolution (the month) have increased.

(Many fragments produced at the time of rupture were undoubtedly captured within a comparatively brief time by the earth and the moon. We may assume, however, that some of the fragments had initial conditions that produced orbital motion around the earth with a period equal to the earth's period of rotation and in the same general direction, i.e., eastward. For a period of revolution of 4 h 8 , the semi-major axis of the orbit would be about 9,000 miles, which is well within the Roche limit, even for the present size of the earth. Harold Jeffreys concludes that the earth has contracted about $1,000 \mathrm{~km}$. since fission; so the Roche limit was greater then than now.

The condition of the primitive earth, whether gaseous, liquid, or solid, is not definitely known, but it is thought that the moon was formed about the time solidification began and that that process was completed within 10,000 years, which is a very small fraction of the age of the moon, estimated to be of the order of $4 \times 10^{\circ}$ years. Jeffreys" suggests that "The place where the moon emerged gave the largest ocean floor; the 'Pacific Ocean is thus regarded as the scar left when the moon was formed." During solidification of the earth, the upper layer, chiefly granite (about six miles thick), and the next layer, chiefly basalt (somewhat thicker), were laid down and the ocean water was extruded. The Pacific basin contains little granitic rock, but its islands, e.g., the Hawaiian, and its floor have much basaltic rock. It seems very probable that the mass of the moon with its mean density very similar to that of the earth's upper crustal layer, stripped the Pacific area of its granite at the time of fission and probably lifted some of the material of the basaltic layer. The glassy basalt or tachylyte, being deepest, was the last to leave the earth and would therefore constitute the material which formed the detached fragments. General similarity of the composition of tektites and glassy basalt, including a high percentage of silicon, is thus explained.

The fragments revolving about the earth within the Roche limit then became swarms of discrete particles, including some with periods coinciding with that of the earth's rotation. If the periods exactly coincided, the swarms would remain directly above the area from which the fragments escaped. It is interesting to note a well-known principle in celestial mechanics that applies at this point. Considering the fragments as separate satellites of the earth, we. find that they would return in their orbits to the point at which they were formed. To simplify the problem, we may disregard the fate of particles with periods greater or less than one day, which may have been captured at a very early period or been entirely lost. The swarms with periods of one day with initial conditions rightly adjusted would remain over the Pacific at a height depending on the point of rupture, possibly much less than 9,000 miles. Perturbations by the moon, slowly falling behind, would tend to decrease the speed of the particles as the rotation of the earth also decreased. Gradually drawn toward the earth these particles would settle into the

2 The Earth, 2nd Ed., p. 300, 1929. 
atmosphere and fall with speeds sufficient to produce the typical forms, characteristic physical features, and original surface markings of the tektites. The velocity, however, would not be the typical parabolic velocity of meteorites, about twentyfive miles per second, which is so high that this mechanical energy, changed into heat, plus friction in the atmosphere, would cause the small ones to disappear, permitting only the larger masses to reach the surface of the earth.

Distribution, in general near the western edge of the Pacific basin, Australia, the Philippines and other islands, Indo-China, and other places on the mainland, may be accounted for by a slight decrease in velocity, due to increasing resistance of the atmosphere at lower levels. The preponderance of tektites in this region seems much more significant than the lesser falls on other parts of the earth. The other showers, however, may readily be accounted for. The David-de Boer great circle of distribution and the Lacroix-Spencer great circle may be considered to lie directly below the orbits of the chief swarms of satellites. The mutual inclination of these orbits and their inclination to the plane of the earth's equator should present no special difficulty. The large inclination of the orbit of the moon to the earth's equator $\left(23 \frac{1}{2}^{\circ} \pm 5^{\circ}\right)$ indicates the sun's influence on the initial conditions and the effect of subsequent action. The orbits of the fragments would be influenced by the combined effect of sun and moon. Falls of tektites farther westward than the west shore of the Pacific, following these two great circles or other possible orbits, represent swarms more retarded in velocity before they finally reached the surface.

The fragments of silica glass larger than the tektites and the meteoritic craters of very early origin, possibly related problems, may readily be considered within the scope of the present theory without separate treatment. Swarms of tektites differing somewhat in mass, silica content, color, form, and other characteristics, would naturally be expected. Difference in the geological periods of the falls may be accounted for by the length of time required for cumulative perturbations, resistance at very high atmospheric levels, and other factors, acting in conjunction with the earth's gravitational attraction, to bring the separate swarms following different orbits down to various parts of the surface.

Although details of the theory cannot be deduced with mathematical precision, it seems to account for the chief facts regarding tektites in a satisfactory way. A large number of articles on the subject have been studied, but we have not found a pertinent fact that seems to be inconsistent. We are submitting the theory for consideration and criticism. ${ }^{3}$

April, 1939

${ }^{3}$ [This paper was originally prepared by Professor Rufus for the Astronomical Society of the Philippines, since his interest in the subject began chiefly during his examination of my large comparative tektite collection and associated literature, in Manila, in 1936, and was continued on the basis of Philippine specimens furnished him for further study. As Professor Rufus requested me to write a brief general review of the tektite question to accompany his paper, and as the subject itself is of interest to several branches of science, it was thought best to present the two papers together at the meeting of the Sixth Pacific Science Congress and also at the July, 1939, meeting of the Philippine National Research Council. The Astronomical Society kindly consented to this arrangement, surrendering its right of priority.-H. O. BEYER, Manila, P. I., July 21, 1939.] 